\title{
ANALISIS TINGKAT PERCAYA DIRI SISWA SMKN 1 KARAWANG BARAT YANG MENGIKUTI PERTANDINGAN FUTSAL
}

\author{
Mochammad Chafid Albiro1, Febi Kurniawan2, Irfan Rahman³. \\ 1,2,3Jurusan PJKR-Universitas Singaperbangsa Karawang \\ e-mail : chafidalbiro123@gmail.com¹ ${ }^{\text {febi.kurniawan@fkip.unsika.ac.id², }}$ \\ irfanrahman9886@gmail.com3
}

\begin{abstract}
Abstrak
Tujuan penelitian ini adalah mengetahui hasil analisis percaya diri siswa yang mengikuti pertandingan Futsal. Subjek dalam penelitian ini adalah seluruh anggota ekstrakurikuler futsal putra di SMKN 1 di Kabupaten Karawang dengan jumlah responden 19 orang. Metode yang digunakan dalam penelitian ini adalah metode discovery. Adapun teknik pengumpulan data menggunakan angket, angket dalam penelitian ini berbentuk skala likert. Hasil penelitian tersebut diketahui Tingkat Percaya Diri Siswa SMKN 1 Karawang Yang Mengikuti Pertandingan Futsal menyatakan pada kategori sangat baik dengan persentase $11 \%$, pada kategori baik dengan persentase $47 \%$, pada kategori cukup baik dengan persentase $11 \%$, pada kategori kurang baik dengan persentase $32 \%$, dan pada kategori sangat kurang baik dengan persentase $0 \%$. Bedasarkan dari hasil tersebut dapat ditarik kesimpulan bahwa Tingkat Percaya Diri Siswa SMKN 1 Karawang terdapat hasil dalam kategori cukup baik dengan persentase 47\%. Dalam kesimpulan tersebut terdapat saran yaitu pelatih terus meningkatkan dalam latihan dan memotivasi siswa agar dapat selalu bersemangat dalam latihan serta meningkatkan mental siswa yang meningikuti pertandingan futsal.
\end{abstract}

Kata Kunci : Pendidikan Jasmani, Percaya Diri, dan Futsal

\begin{abstract}
The purpose of this study was to determine the results of the self-confidence analysis of students who took part in Futsal matches. The subjects in this study were all members of the men's futsal extracurricular at SMKN 1 in Karawang Regency with 19 respondents. The method used in this research is the discovery method. The data collection technique used a questionnaire, the questionnaire in this study was in the form of a Likert scale. The results of the study revealed that the level of self-confidence of SMKN 1 Karawang students who took part in Futsal competitions stated that in the very good category with a percentage of $11 \%$, in the good category with a percentage of $47 \%$, in the category of being quite good with a percentage of $11 \%$, in the poor category with a percentage of $32 \%$, and in the very poor category with a percentage of $0 \%$. Based on these results, it can be concluded that the Confidence Level of Students of SMKN 1 Karawang is in a fairly good category with a percentage of $47 \%$. In the conclusion there is a suggestion that the coach continues to improve in practice and motivate students to be always enthusiastic in training and improve the mentality of students who participate in futsal matches.
\end{abstract}

Keywords : Physical Education, Self-confidence, and Futsal

\section{PENDAHULUAN}

Secara umum olahraga ialah sebagai salah satu kegiatan fisik ataupun psikologis seseorang yang bermanfaat untuk menjaga kesehatan seseorang baik jasmani maupun rohani (Jumadin \& Syahputra, 2019). Olahraga prestasi merupakan olahraga yang membina dan mengembangkan siswa ekstrakurikuler secara terencana, berjenjang dan berkelanjutan dalam mengikuti kompetisi dengan tujuan untuk mencapai prestasi dengan dukungan dan ilmu pengetahuan keolahragaan. Kini olahraga prestasi dijadikan sebagai alat dalam membentuk meningkatkan karakter individu, fisik dan pengetahuan dalam mencapai tujuan untuk meraih prestasi baik antar sekolah, mahasiswa, nasional maupun internasional. Peran olahraga sebagai sebuah mesin untuk membangun karakter kebangsaan seseorang sudah teruji sebab olahraga mempunyai fungsi membangun spirit kebangsaan (Utami, 2015). 
Kini sekarang persaingan olahraga prestasi semakin ketat, prestasi bukan lagi milik perorangan saja, tetapi sudah menyangkut hakikat dan martabat suatu bangsa. Oleh karena itu dalam pencapaian prestasi suatu olahraga menggambarkan hubungan antara pemerintah dan masyarakat olahraga berjalan dengan baik. Itulah sebabnya cara dan upaya dilakukan oleh suatu daerah atau Negara mengupayakan atletnya menjadi juara di berbagai even besar perlombaan olahraga. Ada beberapa faktor sebagai pendukung dan melengkapi kualitas latihan dalam olahraga prestasi yaitu atlet, pengetahuan dan kepribadian pelatih, sarana dan prasarana olahraga, dan ilmu pengetahuan yang menunjang olahraga prestasi (Ashadi, 2014). Apabila dari keseluruhan fakto-faktor tersebut optimal maka dapat meningkatkan performa dan prestasi atlet. Dapat diketuhui bahwa pengetahuan pelatih sangat berpengaruh pada kualitas dalam latihan. Apabila pelatih memiliki pengetahuan yang baik tentang berbagai bidang ilmu kepelatihan maka kualitas latihan akan sangat positif dan optimal. Namun bila pelatih tidak memiliki pengetahuan yang baik maka program latihan olahraga yang dimunculkan hanya berdasarkan pengalaman dari masa lampau.

Futsal merupakan olahraga permainan yang digemari oleh seluruh siswa di sekolah dikarenakan cara melakukan futsal ini sangatlah mudah dan murah, dengan adanya 10 orang pemain saja dan cukup satu bola maka olahraga ini bisa dimainkan. Futsal adalah salah satu cabang olahraga prestasi, dimana banyak masyarakat serta remaja dikala ini yang melaksanakan olahraga futsal sebagai wadah untuk berprestasi (Sepriadi, arsil, 2018). Futsal merupakan salah satu cabang olahraga permainan yang dimainkan oleh dua tim yang masing - masing tim terdiri dari lima orang pemain yang salah satunya adalah penjaga gawang. Tujuan dari futsal itu sendiri bisa untuk hiburan ataupun bisa menjadi hobi yang menghasilkan uang dan cara melakukan permainannya adalah dengan memasukkan bola ke gawang lawan dan mencegah terjadinya gol kegawang sendiri, dengan memanipulasi bola ke kaki. Selain lima pemain utama tadi, setiap regu diperbolehkan memiliki pemain cadangan (Fajri, 2016). Seorang pemain tidak hanya harus kuat fisik dan skill saja tetapi dalam hal lain pecaya diri salah satu faktor yang berpengaruh terhadap pemain futsal. Apalagi pemain futsal profesional, mereka harus perlu juga untuk mengeksplorasi kekuatan percaya dirinya dan mampu mengkombinasikan semua itu untuk kebaikan timnya (Fajri, 2016).

Rasa percaya diri sebagai keyakinan pada kemampuan diri sendiri yang mana percaya diri itu berawal dari alam bawah sadar diri sendiri untuk melakukan segala sesuatu yang diinginkan dan dibutuhkan dalam hidup. Rasa percaya diri lebih menekankan pada kepuasan yang dirasakan oleh seseorang terhadap dirinya, dengan kata lain seseorang yang percaya diri adalah individu yang merasa puas pada dirinya sendiri (Dimyati, 2016). Percaya diri ialah salah satu unsur penting yang perlu diperhatikan dalam olahraga futsal ini. Percaya diri adalah keyakinan akan kemampuan diri, dalam melakukan kegiatan dan merasa sangat optimis, objektif, bertanggung jawab, rasional dan realistis untuk menyelesaikan suatu masalah dengan situasi terbaik (Sin \& Hudayani, 2019).

Meningkatkan kepercayaan diri perlu adanya dukungan baik dari lingkungan keluarga dan lingkungan sekitar seperti orang tua, teman sebaya dan pelatih, dan untuk mengurangi tekanan psikologis seseorang. Keluarga memiliki peran penting bagi perkembangan individu, akan tetapi lingkungan sosial lainnya yakni teman sebaya juga memiliki pengaruh terhadap perkembangan kepribadian individu ketika bermain ataupun bersosialisasi bersama (Sulistiyowati \& Indrawati, 2019). Dukungan emosional dan bantuan lainnya dari orang lain merupakan pengaruh yang penting bagi rasa percaya diri individu. Di dalam olahraga futsal contohnya percaya diri sangatlah berperan penting terhadap permainan seseorang jika percaya diri nya kurang maka permainan juga pasti akan tidak bagus. Tujuan dari penelitian ini untuk mengetahui bagaimana tingkat percaya diri siswa yang mengikuti pertandingan futsal. Karena dalam pertandingan biasanya siswa banyak sekali yang kurang percaya diri yang di sebabkan oleh beberapa faktor salah satunya adalah kurangnya pengalaman bertanding, sehingga siswa yang baru pertama kali mengikuti pertandingan banyak yang tidak percaya diri. 


\section{METODE}

Jenis penelitian ini menggunakan metode survey. Metode survey digunakan untuk mendapatkan data dari tempat tertentu yang alamiah (bukan buatan peneliti) tetapi peneliti melakukan perlakuan dalam pengumpulan data misalnya dengan mengedarkan kuesioner, test, wawancara terstruktur dan lain sebagainya (perlakuan tidak seperti dalam eksperimen).Teknik pengambilan data menggunakan angket. Skor yang diperoleh dari angket kemudian dianalisis dengan menggunakan teknik deskriptif kuantitatif yang dituangkan dalam bentuk persentase. Instrumen yang digunakan dengan membagikan angket ke siswa melalui google form yang telah di buat yang terdiri dari 40 soal angket.

Populasi adalah jumlah keseluruhan dari individu atau obyek yang mana nantinya untuk diteliti dan akan digeneralisasikan (Agustina \& Priambodo, 2017). Populasi ialah sebagai kelompok subyek yang hendak dikenai generalisasi hasil penelitian. Dari pernyataan tersebut penulis mengambil penelitian populasi sebanyak 19 orang peserta yang mengikuti pertandingan futsal. Adapun teknik sampel yang di gunakan adalah sampel jenuh dimana jumlah populasi dan sampel berada di bawah 25 sampel (Wirnantika et al., 2017). Percaya diri dapat di ukur melalui pengisian angket yang telah di buat sesuai dengan aspek percaya diri. Terdapat empat aspek dalam pengisian angket yaitu self concept, self esteem, self efficacy, dan self confidence. Angket atau kuesioner merupakan teknik pengumpulan data yang dilakukan dengan cara memberi seperangkat pertanyaan atau pernyataan tertulis kepada responden untuk dijawab. Kuesioner merupakan teknik pengumpulan data yang efisien bila peneliti tahu dengan pasti variabel yang akan diukur dan tahu apa yang bisa diharapkan dari responden. Kuesioner dapat berupa pertanyaan atau pernyataan terutup atau terbuka, dapat diberikan kepada responden secara langsung atau dikirim melalui pos atau internet (Sugiyono, 2017).

Teknik analisis yanng digunakan adalah teknik anlasisis statistik deskriptif. Dalam perhitungannya dibantu mengunakan microsoft excel 2013, angket yang digunakan dalam penelitian adalah Skla Likert dengan skor positive (favorable) dan skor negative (unfavorable), angket berisi lima kategori tingkat jawaban yaitu sangat baik, baik, cukup, kurang baik, dan sangat kurang baik. Kemudian skor maksimum dan minimum harus ditentukan terlebih dahulu, setelah itu menentukan nilai rata-rata dan standar deviasi skor yang diperoleh. Selanjutnya data disajikan dalam bentuk tabel distribusi frekuensi dan kemudian dilakukan pengkategorian serta menyajikan dalam bentuk diagram batang.

\section{HASIL DAN PEMBAHASAN}

Pada bagian ini akan dijelaskan tentang hasil dan pembahasan penelitian tingkat percaya diri siswa dari kuantitatif sesuai dengan analisis yang telah ditentukan pada bab sebelumnya. Hasil penelitian mencakup deskripsi data dan uji statistik sedangkan pembahasan yang dimaksud yaitu membahas hasil penelitian yang dikaitkan dengan kajian teori. Pengolahan data dilakukan dengan menggunakan aplikasi uji statistik dengan bantuan microsoft excel 2013, dalam hal ini dimaksudkan agar hasil perhitungan dapat dipertanggung jawabkan kebenarannya. Berikut tabel perhitungan hasil angket pecaya diri. Dalam penelitian ini populasi yang digunakan adalah semua peserta siswa SMKN 1 Karawang yang mengikuti pertandingan futsal. Pada penelitian ini peneliti ingin mengetaaui berapa jumlah siswa yang mempunyai percaya diri yang baik. Berdasarkan perhitungan yang dilakukan hasil analisis pada variabel percaya diri, yaitu tingkat percaya diri siswa SMKN 1 Karawang dapat di lihat pada tabel berikut

Tabel 1. Tingkat Percaya Diri Siswa

\begin{tabular}{|c|c|c|c|c|}
\hline \multirow{2}{*}{$\mathrm{N}$} & \multirow{2}{*}{ MEAN } & \multirow{2}{*}{ SD } & \multicolumn{2}{|c|}{ NILAI } \\
\hline & & & MIN & MAX \\
\hline 19 & 161 & 23,6 & 130 & 198 \\
\hline
\end{tabular}


Pengujian ini dimaksudkan untuk mengetahui berapa tingkat percaya diri siswa yang mengikuti pertandingan futsal. Hasil perhitungan dilakukan dengan teknik perhitungan statistik menggunakan program microsoft excel 2013. Berdasarkan perhitungan yang telah dilakukan hasil analisa statistik pada variabel percaya diri, yaitu hasil keseluruhan tingkat percaya diri yang terdiri dari 19 orang dalam penelitian ini data dijelaskan pada tabel berikut:

Tabel 2. Hasil Keseluruhan Tingkat Percaya Diri Siswa

\begin{tabular}{ccccccc}
\hline No & \multicolumn{3}{c}{ Interval } & Frekuensi & Kategori & $(\%)$ \\
\hline 1 & & $\mathrm{X}>$ & 196,40 & 2 & Sangat Baik & $11 \%$ \\
2 & 172,80 & $<\mathrm{X}<$ & 196,40 & 9 & Baik & $47 \%$ \\
3 & 149,20 & $<\mathrm{X}<$ & 172,80 & 2 & Cukup Baik & $11 \%$ \\
4 & 125,60 & $<\mathrm{X}<$ & 149,20 & 6 & Kurang Baik & $32 \%$ \\
5 & & $\mathrm{X}<$ & 125,60 & 0 & Sangat Kurang Baik & $0 \%$ \\
\hline
\end{tabular}

\section{Hasil Keseluruhan Tingkat Percaya Diri}

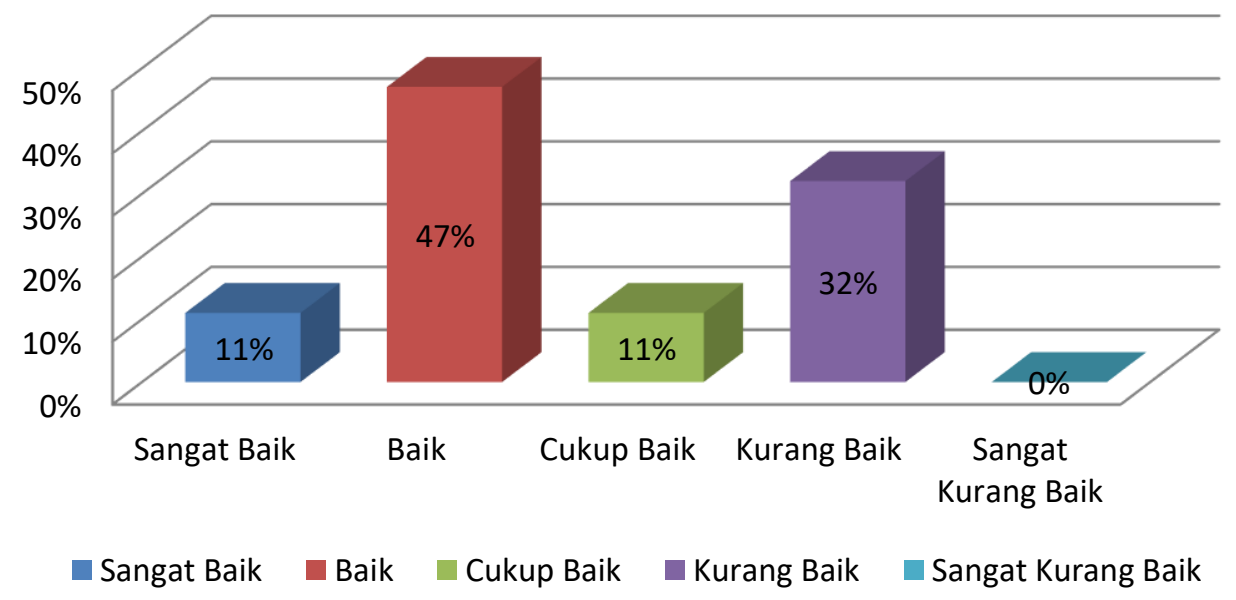

Gambar 1. Hasil Keseluruhan Tingkat Percaya Diri

Faktor hasil analisis percaya diri sendiri secara keseluruhan diukur dengan angket yang berjumlah 40 butir pernyataan dengan skor $1-5$, sehingga diperoleh rentang skor ideal $1-5$. Setelah data diperoleh, diskor, dan dianalisis dengan bantuan software Microsoft Excel 2013, diperoleh nilai minimum $=130$; nilai maksimum $=198$; rata- rata $($ mean $)=161,00$; standar deviasi $=23,60$. Hasil penelitian hasil analisis kepercayaan diri secara keseluruhan tersebut dideskripsikan dengan lima kategori. Pada penelitian ini tingkat kepercayaan diri siswa dinyatakan baik, hal ini dikarenakan siswa yang mengikuti pertandingan futsal adalah siswa yang sudah mempunyai pengalaman yang lama, sehingga mempunyai pengalaman bermain main yang bagus yang pastinya akan mempengaruhi tingkat kepercayaan dirinya. Setiap atlet futsal pasti mengalami gejolak psikologis pada saat menjelang pertandingan. Psikologis yang biasanya muncul pada diri atlet adalah kecemasan, kepercayaan diri dan motivasi yang biasanya muncul pada saat menjelang pertandingan. Penelitian ini bertujuan penelitian ini untuk mengetahui tingka kepercayaan diri pada atlet futsal saat mengikuti pertandingan.

Berdasarkan tabel diatas hasil Tingkat Percaya Diri siswa yang berada kategori sangat baik sebanyak 2 siswa (11\%), pada kategori baik sebanyak 9 siswa (47\%), pada kategori cukup baik sebanyak 2 siswa (11\%), pada kategori kurang baik sebanyak 6 siswa (32\%), dan 
pada kategori sangat kurang baik sebanyak 0 siswa (0\%). Jadi dapat disimpulkan bahwa variabel percaya diri siswa berada pada kategori baik.

Beberapa hasil penelitian menyatakan bahwa tingkat kepercayaan diri remaja berada pada kategori sedang, Hanya beberapa sebagian kecil dari remaja yang memiliki rasa percaya diri yang tinggi (Fitri et al., 2018). sebuah harapan yang tinggi untuk mencapai keberhasilan. Hal tersebut dapat membantu para siswa untuk mengembangkan emosi positif, melatih konsentrasi, menentukan sasaran, meningkatkan usaha, fokus pada strategi pertandingan, dan memelihara momentum (Arham, 2019). Percaya diri berdampak pada proses dimana seseorang memperhatikan, mengelola, dan mengendalikan perilaku, pikiran, emosi dan interaksi mereka dengan lingkungan, termasuk kinerja tugas, tetapi juga termasuk interaksi sosial (Siekanska \& Wojtowicz, 2020). Dalam artian Konsep diri mencakup setiap aspek yang berhubungan dengan diri kita (Misra, 2021).

Percaya diri merupakan kemampuan percaya pada diri sendiri, sehingga pemikiran positif dan pemberian kata-kata pernyataan positif tentang diri sendiri bisa menjadi cara yang sangat baik untuk meningkatkan kepercayaan diri (Wintania et al., 2021). Kepercayaan diri adalah suatu perbuatan atau perasaan yakin atas kemampuan diri sendiri sehingga orang yang bersangkutan tidak terlalu khawatir dalam kegiatanya, dapat merasa bebas untuk melakukan hal - hal yang di senanginya dan bertanggung jawab atas perbuatannya, hangat dan sopan dalam berinteraksi dengan orang lain, dapat menerima dan menghargai orang lain, memiliki dorongan untuk berprestasi serta dapat mengenal kelebihan dan kekurangannya (Novtiar \& Aripin, 2017). Hasil penelitian yang diperoleh dari analisis data penelitian dengan menggunakan analisa data statistik sederhana yaitu dengan mencari rata-rata atau mean. Dengan hasil penelitian tersebut dapat diketahui bahwa kondisi tingkat percaya diri atlet futsal SMKN 1 Karawang sebelum bertanding sebagian besar menunjukkan kategori baik (Arifin \& Widodo, 2012).

Ada beberapa penelitian terdahulu, penelitian yang dilakukan oleh (Sin, 2017), berjudul Tingkat Rasa Percaya Diri Atlet Sepakbola Dalam Menghadapi Pertandingan hasil penelitiannya secara keseluruhan menggambarkan kondisi percaya diri lebih mendominasi pada kategori sedang dengan persentase $40 \%$, dapat disimpulkan bahwa rasa percaya diri sangatlah penting dalam meraih prestasi dan jika rasa percaya diri yang rendah dapat berpotensi dapat menimbulkan prestasi yang rendah juga. Dan penelitian yang dilakukan oleh ,(Hardi et al., 2020), yang berjudul Tingkat Percaya Diri Atlet Panahan Cimahi Mandiri Archery Club hasil penelitiannya menunjukan tingkat percaya diri atlet panahan cimahi mandiri archery club termasuk kedalam persentase $88,89 \%$, maka tingkat percaya diri sangat berperan kepada atlet karena dapat mengotrol secara penuh kondisi emosional atlet itu sendiri

\section{SIMPULAN DAN SARAN Simpulan}

Berdasarkan hasil analisis dan pembahasan tentang "Analisis tingkat percaya diri siswa SMKN 1 Karawang yang mengkuti pertandingan Futsal maka dapat ditarik kesimpulan sebagai berikut. Berdasarkan Hasil Analisis Tingkat Percaya Diri siswa yang berada kategori sangat baik sebanyak 2 siswa (11\%), pada kategori baik sebanyak 9 siswa (47\%), pada kategori cukup baik sebanyak 2 siswa (11\%), pada kategori kurang baik sebanyak 6 siswa (32\%), dan pada kategori sangat kurang baik sebanyak 0 siswa $(0 \%)$. Jadi dapat disimpulkan bahwa variabel motivasi siswa berada pada kategori baik.

\section{Saran} berikut :

Dari kesimpulan tersebut maka terdapat beberapa saran yang akan dijabarkan sebagai

1. Bagi sekolah dapat memberikan fasilitas yang lebih dan memberikan apresiasi kepada siswa yang mengikuti pertandingan futsal agar siswa tersebut tambah bersemangat dalam latihan. 
2. Bagi pelatih terus meningkatkan dalam latihan dan memotivasi siswa agar dapat selalu bersemangat dalam latihan serta meningkatkan mental siswa yang meningikuti pertandingan futsal.

3. Bagi siswa terus bersemangat dalam latihan agar menjadi juara dan jika meneruskan kejenjang pendidikan perguruan tinggi negeri dapat lebih mudah untuk mendapatkanya

\section{DAFTAR PUSTAKA}

Agustina, A. T., \& Priambodo, A. (2017). Hubungan Antara Tingkat Konsentrasi Terhadap Hasil Ketepatan Shooting Olahraga Petanque Pada Peserta Unesa Petanque Club. Pendidikan Olahraga Dan Kesehatan, 5(3), 391-395.

Arham, S. (2019). Kontribusi Kekuatan, Kecepatan, Kelincahan Dan Percaya Diri Terhadap Keterampilan Teknik Pada Permainan Futsal. Exercise : Journal of Physical Education and Sport, 1(1), 10-24. https://doi.org/10.37289/exercise.v1i1.20

Arifin, Z., \& Widodo, A. (2012). Kondisi Mental Siswa Putra Satu Hari Sebelum Menghadapi Pertandingan Futsal Antar SMA Se Sidoarjo. Journal Kesehatan Olahraga, 01(03), 1-5.

Ashadi, K. (2014). Implementasi Fisiologi Olahraga pada Olahraga Prestasi. Hotel Horison Ultima Jl Green Boulevard, 65125(2), 59-70. www.healthyperformance.co.uk,

Dimyati, A. (2016). Keterampilan Jumping Service: Hubungan Antara Daya Ledak Otot Lengan, Koordinasi Mata-Tangan, Dan Rasa Percaya Diri. 4(November), 219-230.

Fajri, M. (2016). Hubungan Antara Kekuatan Otot Tungka, Kecepatan Lari, dan Percaya Diri Terhadap Keterampilan Menggiring Bola Pada Siswa Ekstrakurikuler Futsal SMP Daar EI Salam. Lentera: Jurnal IImiah Kependidikan, 2, 139-156.

Fitri, E., Zola, N., \& Ifdil, I. (2018). Profil Kepercayaan Diri Remaja serta Faktor-Faktor yang Mempengaruhi. JPPI (Jurnal Penelitian Pendidikan Indonesia), 4(1), 1. https://doi.org/10.29210/02017182

Hardi, V. J., Budiman, A., \& Riyadi, I. (2020). Tingkat percaya diri atlet panahan Cimahi Mandiri Archery Club. Journal of Physical and Outdoor Education, 2(2), 221-227.

Jumadin, \& Syahputra, R. (2019). Analisis Olahraga Prestasi Yang Dapat Di Unggulkan Kabupaten Langkat. Jurnal Kesehatan Dan Olahraga, 3(1), 10-19.

Misra, J. (2021). A Study On The Relationship Between Self- Concept and Self- Confidence Level Of Adolescent Students. 8404-8406. https://doi.org/https://doi.org/10.17762/pae.v58i2.3481

Novtiar, C., \& Aripin, U. (2017). Meningkatkan Kemampuan Berpikir Kritis Matematis Dan Kepercayaan Diri Siswa Smp Melalui Pendekatan Open Ended. Prisma, 6(2), 119-131. https://doi.org/10.35194/jp.v6i2.122

Sepriadi, arsil, A. D. . (2018). Pengaruh Interval Training Terhadap Kemampuan Daya Tahan Aerobik Pemain Futsal. Jurnal Penjakora, 5(2), 121-127. https://ejournal.undiksha.ac.id/Index.Php/Penjakora/Article/View/17288/10379

Siekanska, M., \& Wojtowicz, A. (2020). Impulsive athlete as a self-regulated learner. Can selfconfidence and a positive social attitude change a developmental inhibitor into a growth catalyst? Journal of Physical Education and Sport, 20(2), 623-629. https://doi.org/10.7752/jpes.2020.02091

Sin, T. H. (2017). Tingkat Percaya Diri Atlet Sepak Bola dalam Menghadapi Pertandingan. Jurnal Fokus Konseling, 3(2), 163. https://doi.org/10.26638/jfk.414.2099

Sin, T. H., \& Hudayani, F. (2019). Efektifitas metode belajar renang dengan bantuan teman 
untuk meningkatkan kepercayaan diri atlit. Jurnal Aplikasi IPTEK Indonesia, 3(3), 168173. https://doi.org/10.24036/4.33355

Sugiyono. (2017). Metode Penelitian Kuantitatif, Kualitatif, dan R\&D. Alfabeta.

Sulistiyowati, \& Indrawati, E. S. (2019). Hubungan antara dukungan teman sebaya dengan kepercayaan diri pada pemain futsal universitas diponegoro. Empati, 8(1), 21-26.

Utami, D. (2015). Peran Fisiologi Dalam Meningkatkan Prestasi Olahraga Indonesia Menuju Sea Games. Journal Olahraga Prestasi, 22(2), 52-63.

Wintania, F. A., Mulyadiprana, A., \& Ganda, N. (2021). Penerapan Model Pembelajaran Cooperative Learning Tipe Think Pair Share Dalam Meningkatkan Sikap Percaya Diri Pada Keragaman Budaya Indonesia. 8(1), 183-192.

Wirnantika, I., Pratama, B. A., \& Hanief, Y. N. (2017). Survey Tingkat Kebugaran Jasmani Siswa Kelas IV SDN Puhrubuh I dan MI Mambaul Hikam Di Kabupaten Kediri Tahun Ajaran 2016/2017. Jurnal Pembelajaran Olahraga, 3(2), 241-250. 